\title{
Research on Track and Field training System Based on Network Technology
}

\author{
Dexue Feng \\ Ankang University.Shanxi.China \\ E-mail:dexuef210@163.com
}

\begin{abstract}
Track and field training is a practical and highly participatory training and learning of bilateral activities, less network resources compared to other disciplines, and the lack of systematic and complete. So in this context, relying more mature college campus network, based on Internet technology, computer technology, multimedia technology, modern communication technology, design and development of an briented the track and field network training platform is very necessary. Based on computen network technology, multimedia technology and modern communications technolog., this paper designs and develops interactive network training platformfor the college track and field training and track and Field daily management.
\end{abstract}

Keywords: Track and field education, NetworkteChnology; network training platform

\section{Introduction}

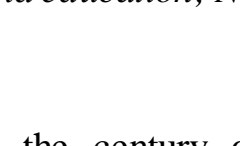

Twenty-first Century is the century of Papid development of network, with the development of computer technology network technology and modern educational technology, educational informatization' development make a spurt of progress. Our university network training as the rapid development of training informatization, it has attracted moreand more attention in education. At present, China's network training in universities has penetratedjinto many fields, track and field training and track and field training should also follow the development of network education, network training and speeding up the trackand field track and field development of network training, training pattern to form multiple channels, optimize the training of track and field training of track and field education. Network in College track and field training is based on the purpose of deepening development, to the development of College track and field training network system as the research object, using literature method, survey method, software development method.

Network track and field training is a new form centered on the active development of learners, making distance learning and continuing training easier than ever. Compared with the traditional education, network track and field training greatly improves the quantity, quality and speed of network transmission. In the virtual world, following the training mode characterized by visualization, stereoscopic sense and substance sense, it can not only activate students' thinking, stimulate their study enthusiasm and initiative greatly, but cultivate their self -exploration spirit, practical interest and ability. So its educational advantages are obvious.

\section{The Basic Category and Logical Structure of Track and Field Training}

We summed up the following basic category of the Track and Field training and training through the investigation of the concept and category of track and Field training 
and training study: Track and Field training and sport (track and Field), track and Field training and movement training, teachers and students, coaches and athletes, training content of Track and Field training and track and Field training content, training methods of Track and Field education, methods and means of track and Field training, objectives of Track and Field training and track and Field training goal etc. Track and Field training and training category is the knot to help people understand the track and Field training and movement training network. And category link is the path to help us understand the training and training process. Category system is the thinking tool to help people grasp the whole Track and Field training and training. So the category system of Track and Field training and training plays an important part of helping people to understand the track and Field training and movement training [1]. The logical structure of basic category system in Track and Field training and training, is a dynamic three-dimensional structure composed of the starting point, intermediary and terminal category which have mutual connection, mutual influences and interaction with each other in the process of developing from the simple to the complex, from the beginning to the end and from the abstract to the concrete.

In this structure, the starting point of Track and Fiele training and training is the movement. The central category is the track and Field training and track and Field training. Intermediary category is the subject and object of the track and Field training and movement training. The terminal category is the goal of track and Field training and movement training [2]. Study on these bas categories should be expanded in the system structure of the entire category systemand interaction of each basic category, in order to determine the content, role and characteristic of each category. Meanwhile, confirming that each category is arranged if opder and assøciate with each other closely so that they can reproduce the logical process which dexelops from the simple to the complex, from the abstract to the concrete as shown in Table

\begin{tabular}{l} 
Table 1. Part of the Structure index in Different Periods of Cooperation \\
\begin{tabular}{|l|c|c|c|c|c|}
\hline \\
Network
\end{tabular} \\
\hline Sum of organizations \\
\hline Selected threshold
\end{tabular}




\section{The Modern Network Training Model}

Track and field network training promotes the formation and supplement of classroom training for teachers and students mainly according to the requirements of school track and field education. It breaks the traditional training mode of school track and field, regardless of time constraints, and constitutes a diversified training track and field training system together with classroom education, broadcasting training and television education. This article focuses on the research of Track and field Network Distance training based on the internet network and telecommunications network. The so-called network training is a new stage for the training development, and it is a form of training different from a traditional school training and full-time education. The modern network training which rises in the late 1990s can be chose from the students themselves in the form of receiving through computer networks or direct transmission of through network communication technology. As shown in Figure 1.

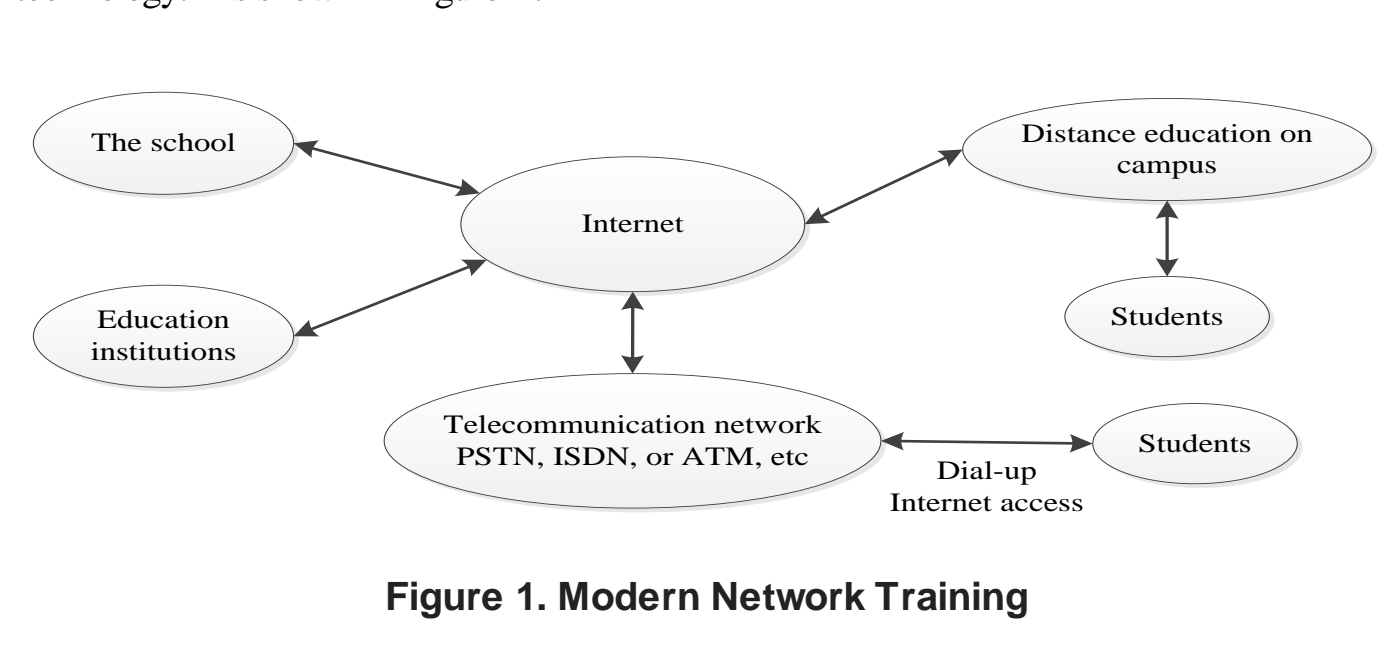

\section{The OverallModel Designfor Track and Field Network Training Platform}

The purpose for the design of track and field network training platform is to provide the user an internet-based network learning environment. Functions the platform needs to realize are achieved by the interaction between application server and the user's browser. There are a variety of network and data stored in the system track and field online training platform, including student network, Track and field pictures, track and field action technology demonstration videos, track and field training writing materials, student interactive message, track and field network test scores, etc. These data are stored in the form of data in different formats in the database server, and organized and maintained by the database server. The following Figure 2 is a schematic of track and field network training platform application mode.

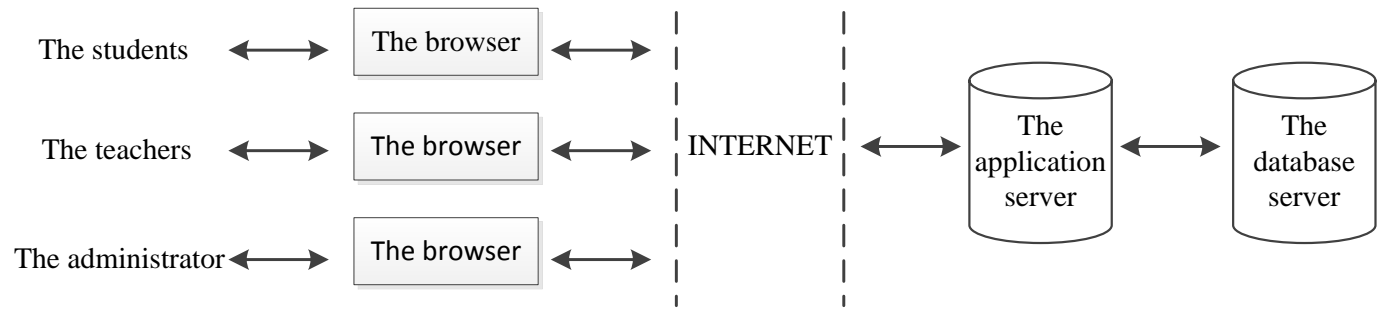

Figure 2. Track and Field Network Training Platform 


\subsection{Network Technology in The Training of Optional Track and Field}

Track and field theory of network platform using the latest B/S (Browser / server) structure, the structure shown in Figure 3 .The following characteristics of the structure: client application environment for the standardized generic Web browser, all applications are stored on a Web server, and can be downloaded directly; easy to management and maintenance, because the client does not need special software, when to upgrade the network application, only need to update the server software this structure has good expansibility and openness, B/ S structure with a standard by using the standard communication protocol of the TCP/IP, the school according to its own development needs to expand the system at any time .

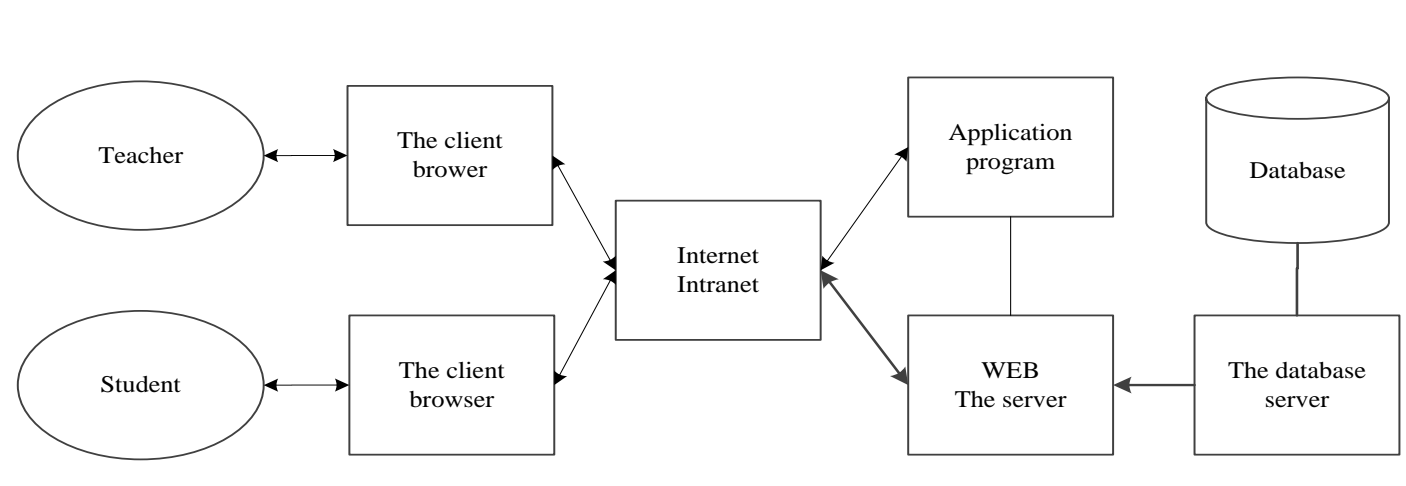

Figure 3. Network Training Platform Structure

\subsection{Technology Structure of Track and Field Training and Training System}

Generally speaking, the key technologies in the design of the track and Field training system construction inclade two broad categories: multimedia communication technology and information technology. Information network, the terminal equipment and teaching resources constitute the technical system of education.as shown in Figure 4.

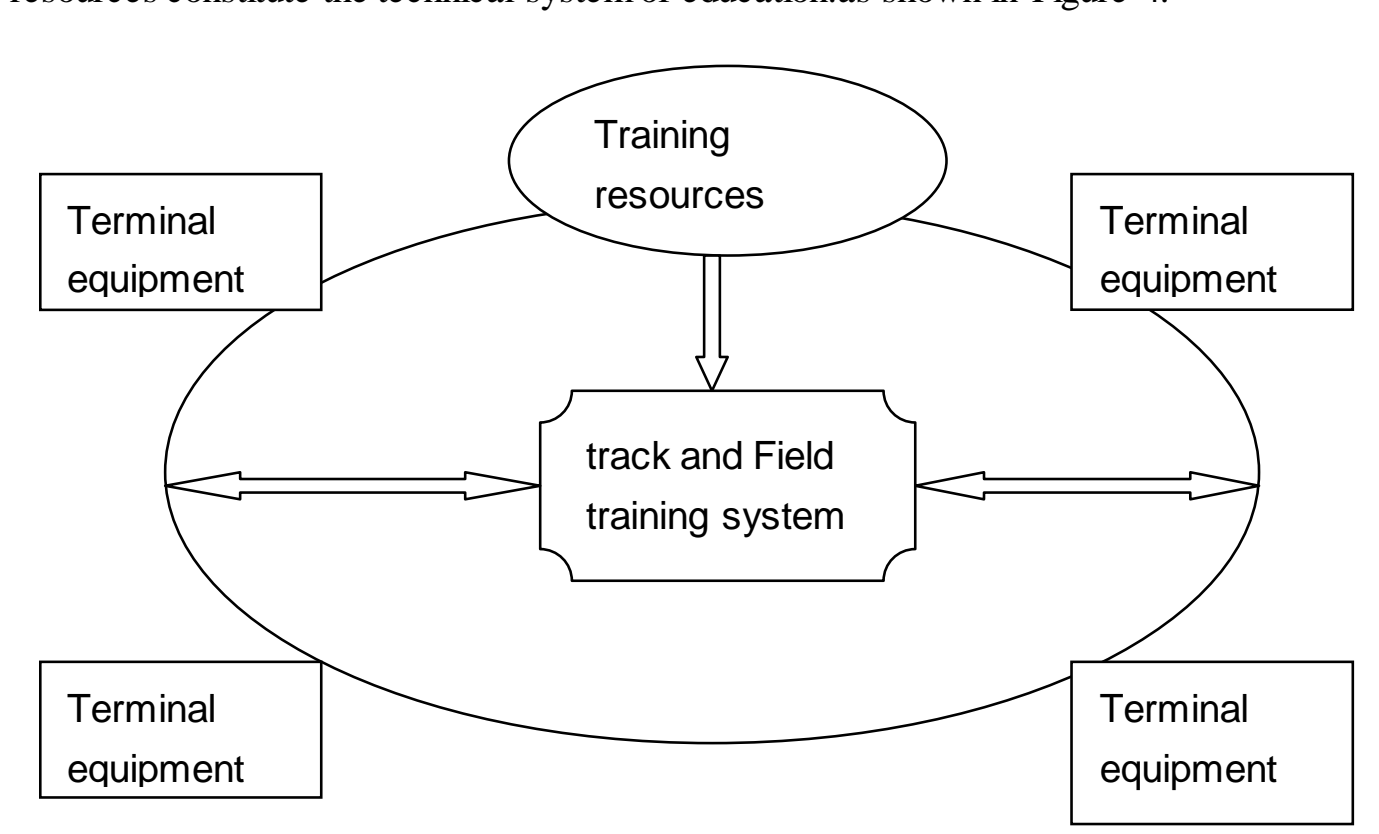

Figure 4. Track and f Training and Training System 
Information network and terminal equipment consist of hardware supporting environment of track and Field training system, which are the basis and guarantee to do Track and Field training and training so as to help students obtain training and training services. Information network links independent terminal device and decentralized network so that they can communicate and share information with each other. And the terminal device can receive information, process a variety of information resources [3] and then transmit them to students. As the software system of network training and training system and core of the system, terminal device produces knowledge influences on students directly.

Network training is a new form centered on the active development of learners, making distance learning and continuing training easier than ever. Compare d with the traditional training, network teaching greatly improves the quantity, quality and speed of information transmission. In the virtual world, following the teaching mode charaqterized by visualization, stereoscopic sense and substance sense, it can not only aetivate students' thinking, stimulate their study enthusiasm and initiative greatly, but cultivate their self -exploration spirit, practical interest and ability. So its educatonal advantages are obvious [4].

The department in charge should plan for the establishment/of special Track and Field training and training organization to ensure the effeetive implementation of the network training and training. The task of the spectalized agency is to ensure the normal development of training and training, establish and maintaun three network training sub systems, which play various roles. Therefore they become the prerequisite to develop network training and training.

The first is the network trairing and traning management subsystem, which is responsible for the construction of educational aeministration, teaching control, resource development and quality assurance system order to coordinate the various teaching activities of information dissemination, Tearn to support service personnel and the police, and coordinate the relationship betweenthe training system and learning environment, etc. [5]. The main work includes comprehensive planning and determining the network training and training content arrangement, teaching requirements and teaching methods, organizing the selection of teachers and pre-professional training for teachers.

The second is the network training and training information subsystem, an instruction execution system, ingluding the network teaching resources database and teaching resources of the network information exchange system. The main task is to help strengthen teaching resources information exchange and network communication between teachers and students. Meanwhile, the link among teaching resources should be established to realize the remote information communication through the network [6].

The third is network training and training supporting service system, an important part of constructing the network training and training system. Responsible for the technical operation of the network teaching system, it provides all kinds of network learning counseling, guidance and assistance service, aiming to establish a comprehensive, effective and perfect learning supporting service system.

\subsection{The Function of Network Technology in Improving Students' Motor Skills}

In the process of practical track and field training, some active techniques not only own complex track and field structure, but also need to be performed instantaneously. When the difficult technical links, animation or image are shown clearly with the combination of slow motion, video pausing, replay, explanation and demonstration through the network software, the training objects can see the technical details of every moment of action clearly and teachers can explain the main points of each decomposition of movement, demonstrate the whole process of the action then they can grasp the key part of the action 
and highlight the keys and difficulties. The use of network technology, for example, showing some sides and $\mathrm{s}$ of various motor techniques, technical difficulties, keys and common faults to students when they are training, making analysis and comparison with students, putting forward and solving problems, can help training objects establish the active representation faster, improve the efficiency of action learning of cognitive stage and improve track and field skills in a short period of time.

\subsection{Advantages of Network Technology Applied in Track and Field Training}

Without being limited by time and space, network technology can effectively combine all training network such as text, image, sound and animation together, convey to the educatees' sensory organs to achieve the efficient transmission of educational network in the track and field training, which can motivate the students to engage in such activities actively as observation, experiment, conjecture, creating (Modeling), verification, reasoning, communication and problem solving, change stidents learning styles, implement student's subject status, change the training fole and construct the new relationship between teachers and students. As a modern training method in network technology, network computer-aided track and field training and training is of great significance in optimizing the track and field training and training, stimulating students' motivation and interest in track and field training, enhancing students' understanding of the concept of action and knowledge of track and fieldotheory and improve the quality of track and field education. With image, animation, video, voice and other reflecting dynamic changing process of the technical moverent, teachers can attract students' auditory and visual senses and jnduce students' thinking to achieve the purpose of inspiring students' learning motivation.

One of the characteristics of track and field network training is the real-time communication technolog Track and field network training platform has a very strong function of sharing network resources. Timely communication between teachers and students is beneficial to the smooth progress of track and field training [7]. In the period of traditional track and field training in colleges and universities, since training takes a class as a unit, the number of students are a lot, the communication between teachers and students is restrieted, while by using the multimedia network training platform, students and teachers can communjeate and interact with each other online. With the support of track and field network training technology, it can make the students and teachers realize the "face to face communication. In this way it can better improve the interaction between training and learning, improve the level and efficiency of the training.

\subsection{Providing Personalized Learning Space for the Students}

Usaally the training subject of the traditional college track and field training is focused on teachers, classroom and training materials, due to the limitation of the number of students and training time, college track and field training is difficult to carry out targeted personalized instruction and training, which leads to the difficulty of realizing students' independent and individualized learning. Through the application of track and field network training in track and field training, students can conduct self-learning and personalized learning through the training resources network database of track and field network training platform, which can break through the limitations of traditional track and field training in Colleges and universities in time and space, realizing the personalized training that the students are really regarded as the main subject of learning.

\subsection{Realizing the Sharing of College Track and Field Training Resources}


The application of track and field network training in College track and field training brings about new reform and innovation for network resources sharing and optimization of college track and field training network. Track and field network training platform provides a variety of network resources database with a collection of world advanced schools, researching institutes, such as library, etc. for college track and field training. The type of the online resource of track and field training has many kinds, including all track and field training news, all kinds of statistic data, the database of track and field researching paper, etc. On the Internet, training content, training materials, training methods and training auxiliary methods, how to carry out the environmental construction of track and field network (such as visiting, doing experiments) and test, etc. can be chosen according to the different person and different demand, with strong independent choice, so as to realize the sharing of resources.

\subsection{Improving the Training Efficiency of Track and Field Teachers'}

In many universities and colleges, college track and field course has free demand for the track and field teachers, but in reality, it is difficult for one teacher to have overall understanding about the technical action and show-perfect demonstration of all track and field items. Thus, track and field training is hampered by many obstacles and factors of teachers' ages, teachers' gender and teachers' personal abilities, elc. By using multimedia network training platform, it can conduct standardized demonstration for track and field training, so as to ensure students can receive the completeness and correctness of the network.

\subsection{Improving in Students' Observation, Practicé and Innovation Ability}

Without being limited by time and space, network technology can effectively combine all training network such as text, image, sound and animation together, convey to the educatees' sensory organs to achieye the efficient transmission of educational network in the track and Field training, which can motivate the students to engage in such activities actively as observation, experiment, conjecture, creating (Modeling), verification, reasoning, communication and problem solving, change students' learning styles , implement student's subjecl status, change the training role and construct the new relationship betweencteachers and students [8]. As a modern training method in network technology, multimedia computer-aided track and Field training and training is of great significance in optimizing the track and Field training and training, stimulating students' motivationand interest in track and Field training, enhancing students' understanding of the concepto action and knowledge of track and Field theory and improve the quality of physicat education. With image, animation, video, voice and other media reflecting dynamic changing process of the technical movement, teachers can attract students' auditory and visual senses and induce students' thinking to achieve the purpose of inspiring students' learning motivation.

\subsection{Improving Students' Ability to Analyze and Solve Proble ms}

The training mode that students practice according to teachers' explanation and demonstration is predominantly adopted in the traditional physical education. Educational psychology research shows that the most practical and active factor of learning motivation is the recognition of interest. The knowledge people in full interest studied is often grasped quickly and firmly. Under the influence of the traditional mode of physical training "the absolute authority of the teachers ",which emphasizes teachers' active transmission and students' passive absorption instead of training students in accordance with their aptitude, students can only absorb knowledge and training methods through 
teachers' fixed mode of thinking, which limits students' space of thinking and their initiative in learning and training. While we'd better apply modern network technology to track and Field training, put various physical knowledge, motor techniques , technical difficulties, keys, common wrong actions into the track and Field training software with which you can cultivate initiative and enthusiasm of students' learning and exercise , improve the students' ability to analyze and solve problems in the process of discussing, proposing, analyzing questions, solving problems and participating in practice. It will improve students' comprehensive quality to apply network technology to track and Field training and training, improve track and Field training content and training method of training. That is to say, the learner-centered training method of training should be adopted.

\subsection{Improving Stude nts' Motor Skills}

In the process of practical track and Field training, some track and Field techriques not only own complex track and Field structure, but also ${ }^{\circ}$ need to be performed instantaneously. When the difficult technical links, animation or image ane shown clearly with the combination of slow motion, video pausing, replay, explanation and demonstration through the multimedia software, the training objects can see the technical details of every moment of action clearly and teachers can explain the main points of each decomposition of movement, demonstrate the whole process of the action. Then they can grasp the key part of the action and highlight the keys and difficulties. The use of network technology, for example, showing some sides and coursewares of various motor techniques, technical difficulties, keys and common faults to students when they are training, making analysis and domparison with students, putting forward and solving problems, can help training objects establishthe motion representation faster, improve the efficiency of action learnifg of cognitive stage and improve track and Field skills in a short period of time.

\section{Investigating Objects}

This research selected two kind of students as the investigating objects, first is the postgraduate with training program in track and field Institute of Higher Normal University in China Whose major is P.E. training, selecting the students who are in postgraduate training program from track and field Institute of Beijing Normal University, track and field Institute of Northeast Normal University, track and field Institute of Huazhong Nórmal University, track and field Institute of East China Normal University, track and fleld Institute of Southwestern University (Southwestern Normal University is combined with Southwest Agricultural University, known as Southwestern University), trackand field Institute of Shanxi Normal University track and field Institute, taking the postgraduates from the six representative key institutions of the universities as the investigating objects.

\section{The Design of the Questionnaire}

According to the researching content and purpose, in view of the problems involved with the questionnaire structure that is in strict accordance with track and field scientific researching method and the basic requirements of designing questionnaire, and then combined with expert's opinions and suggestions in detail, modifying carefully, after checking the forecast test, reliability and validity, finally it designed two sets of questionnaires combined with the specific implementation of the objects in this paper thesis. 


\section{Test the Reliability of the Questionnaire}

To test the reliability of the two questionnaires, this thesis adopted "retest method" to test the reliability of questionnaires, conducting two questionnaires with a certain problem within the intervals of two weeks, and analyzed it according to the test results of the two times. The correlation coefficient of the two tests is 0.962 and $0.958,(p<0.01)$, which indicated that the two questionnaires designed in this thesis had higher reliability (shown in Table 2 and Table 3).

Table 2. Questionnaire One the Table of Reliability Test

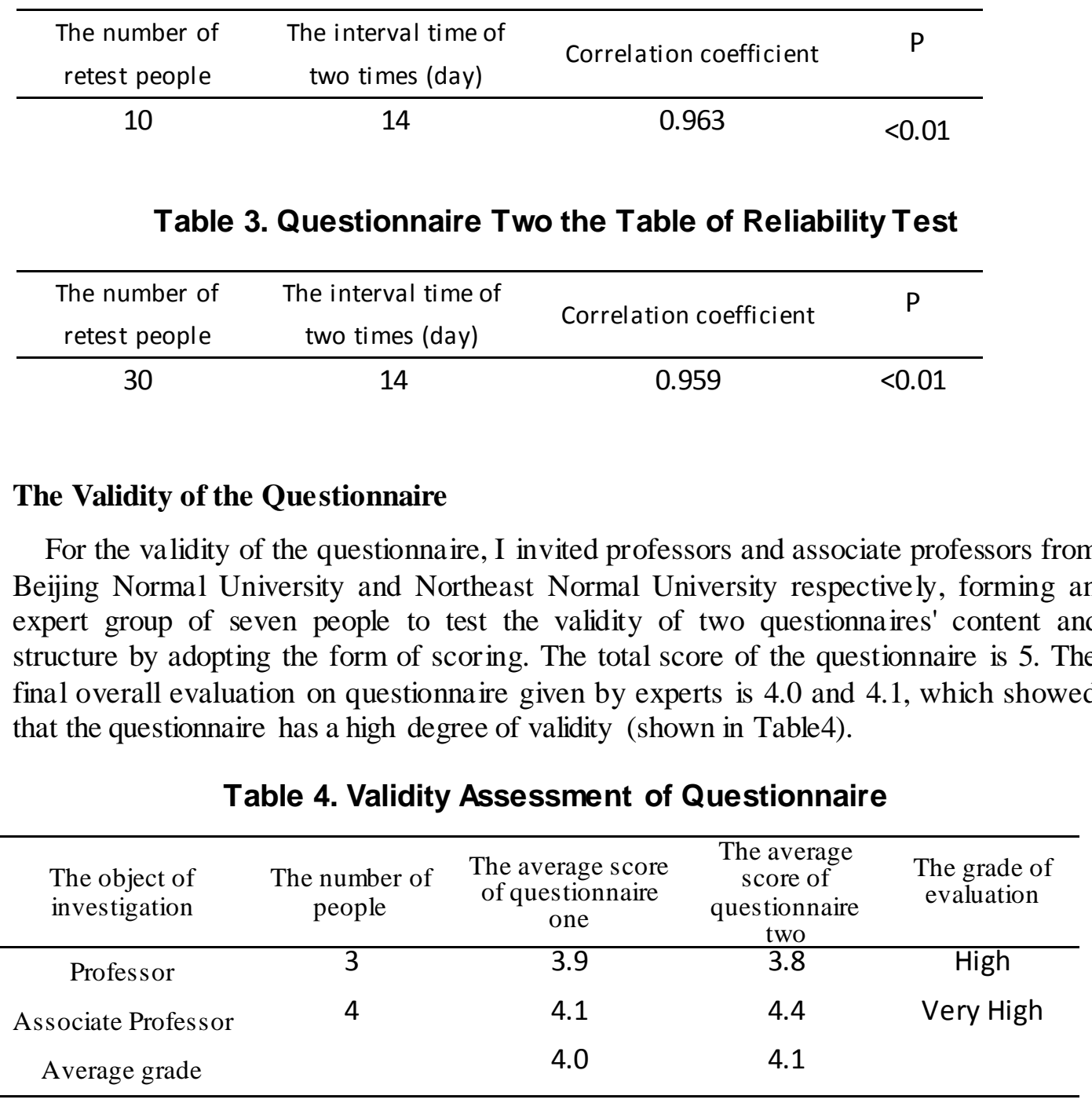

\section{Conclusion}

The application in network training in college track and field training brings a new innovation for college track and field training network resource sharing and optimization. Network training platform provides a large database for college track and field training which collects a various network resources around the world in advanced schools, institutes and libraries. Because of the type of online track and field training resource, including all aspects of track and field training news and network, all kinds of track and field training statistics, track and field and research papers libraries, and the difference on the internet of training content, training materials, training methods, auxiliary training 
methods, and how to conduct online track and field environment training (such as visits, laboratory), people have a independent selectivity and can realize the sharing of resources.

\section{References}

[1] H. Wu, "The development of China's track and field training", Journal of track and field, vol. 8, no. 1, (2001), pp. 8-9.

[2] Y. Chen, "Ordinary university track and field network training platform design and implementation", Beijing university of posts and telecommunications, (2010).

[3] L. M. Na, "The development of network training in our country present situation and problem analy sis", Science and technology Interest rates, no. 20, (2010), pp. 608-610.

[4] C. Guo, "The development of network training in our country and existing problems analy sis", Journal of network education, no. 2, (2009), pp. 81-83.

[5] L. Quan, "The design and implementation of a training system", China normal university, (2008).

[6] R. Feng, "Network training culture connotation and characteristics of the", Journal of ele perochemical training research, no. 7, (2003), pp. 29.

[7] L. Furong, "Research on Islanding Detection Methods of Single-phase Grid Connected Photovoltaic Systems", Wuhan: Huazhong University of Science \& Technology, (2008).

[8] Y. Qiuxia, Z. Qinglin and G. Xiaoqiang, "Modeling and Analysis Of Current-disturbance Based Islanding Detection For Three-phase Photovoltaic Grje-connected Inverters", Automation of Electric Power Systems, vol. 36, no. 4, (2012), pp. 45-49.

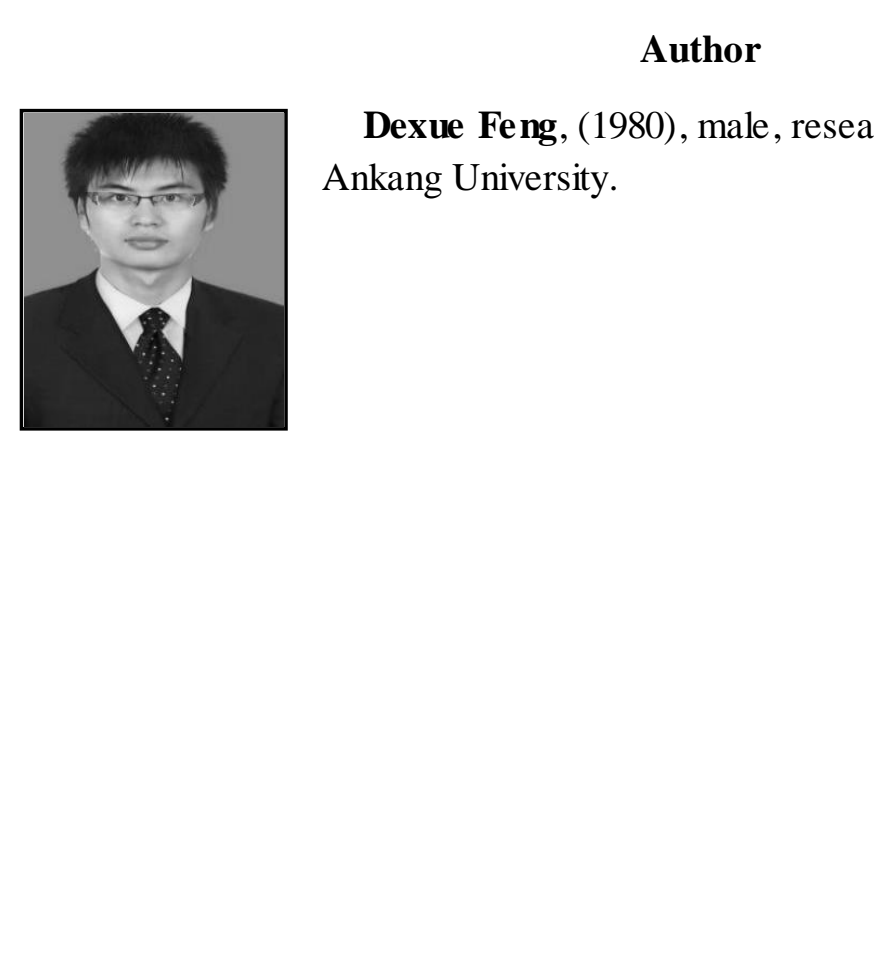

